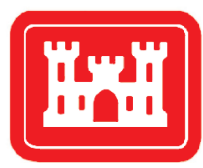

US Army Corps of Engineers ${ }_{\circledast}$

\title{
AlS Data Case Study: Quantifying Connectivity for Six Great Lakes Port Areas from 2015 through 2018
}

\section{by Marin M. Kress, David L. Young, Katherine F. Chambers, and Brandan M. Scully}

PURPOSE: This Coastal and Hydraulics Engineering Technical Note (CHETN) presents results from a preliminary examination of commercial vessel traffic connectivity between six major port areas on the Great Lakes using Automatic Identification System (AIS) data collected from 2015 to 2018. The six port areas included in this study are Calumet Harbor, IL and IN; Cleveland, OH; Detroit, MI; Duluth-Superior, MN and WI; Indiana Harbor, IN; and Two Harbors, MN. These six locations represent an important subset of the more than 100 federally authorized navigation projects in the Great Lakes maintained by the US Army Corps of Engineers (USACE). The results are presented in the context of USACE resilience-related policy initiatives as well as the larger topic of maritime system resilience.

INTRODUCTION: Resilience is defined by the USACE as the ability to Prepare, Absorb, Recover, and Adapt (PARA) (USACE 2017). Recent USACE policy has established that resilience thinking should be implemented across the agency (USACE 2020). At the project or system level, this means that resilience evaluations should be completed using resilience principles at the planning or design stage to ensure that it can withstand large overloads then essentially recover to its original state and function after the overloading event (USACE 2020). Further, the policy states where necessary resilience evaluations of project plans should be completed and documented, and that "interconnections between project components and systems, and their individual and cumulative effect on project performance and resilience... should be considered" (USACE 2020). In the absence of established metrics to measure resilient performance, the properties of the PARA principles - like robustness, redundancy, and reliability - can serve as a starting point to evaluate maritime transportation systems (Aven 2017; Omer et al. 2012; Asadabadi and Miller-Hooks 2020). Typically, the USACE utilizes metrics like total tonnage and specific commodity tonnage to rank and define the performance of waterways. This case study builds on these metrics by recommending further ways to assess a system. First, the dominant commodity type, tonnage, and vessel types moving through each port are defined - a measure of capacity utilization. Then, a network analysis methodology is employed to define a portion of the Great Lakes navigation system in a new way: by its port-to-port connectivity. Connectivity is a metric that describes multiple properties of the system, its geographic reach and its interconnectivity as defined by the traffic levels between ports in the system. Connectivity has previously been used to measure supply chains and port systems (Lam and Yap 2011;

Pavlov et al. 2019. When combined with the type and tonnage of commodities moving on these vessels, potential redundancies between ports, robustness across the supply chains, and the impacts of seasonality are revealed. This knowledge can inform a better understanding of the resilience of the navigation system elements that USACE maintains, which provide the nation with reliable access to the important commodities that move across the Great Lakes. 
To date there has been little examination or quantification of maritime connectivity using AIS data from the Great Lakes region. This CHETN presents preliminary results summarizing monthly vessel movements between six major Great Lakes port areas (Calumet Harbor, IL and IN; Cleveland, OH; Detroit, MI; Duluth-Superior, MN and WI; Indiana Harbor, IN, and Two Harbors, MN) starting in January 2015 and continuing through the end of December 2018. Summary tonnage information for these port areas is presented in Table 1. The basis for this analysis is timestamped and geospatially referenced vessel position, speed, heading, and identification information available from broadcasts captured by AIS transponders now carried by most commercial vessels in the United States. Since 2016, AIS carriage requirements have included most commercial self-propelled vessels on US navigable waters; this includes any vessel over $65 \mathrm{ft}^{1}$ in length, towing vessels over $26 \mathrm{ft}$ in length with an engine greater than $600 \mathrm{hp}$, vessels certified to carry 150 or more passengers, dredges in or near a commercial channel, and vessels moving certain dangerous cargo (USCG 2018; US Code of Regulations 2019). Extensive information on AIS specification can be found through international associations that set technical standards (IALA 2008; IEC 2001; ITU-R 2014; PIANC 2019). The US Coast Guard (USCG) Nationwide Automatic Identification System (NAIS) program archives AIS records from coastal and inland areas received by shoreside towers. These archived AIS records have been used to research waterway utilization (Kress et al. 2020; Mitchell and Scully 2014; Young and Scully 2018) as well as in maritime resilience topics (Scully and Chambers 2019; Touzinsky et al. 2018).

\begin{tabular}{|l|l|l||}
\hline \multicolumn{3}{|l|}{ Table 1. Total tonnage for selected Great Lakes Port or Waterway, 2018. } \\
\hline \hline Great Lakes Port or Waterway Area & $\mathbf{2 0 1 8}$ Total Tonnage & $\begin{array}{l}\text { 2018 Top Commodity: } \\
\text { Tonnage }\end{array}$ \\
\hline $\begin{array}{l}\text { Calumet Harbor and River, IL and IN } \\
\text { (Waterway) }\end{array}$ & $9,297,384$ & $\begin{array}{l}\text { Asphalt, Tar, and Pitch: } \\
1,209,842\end{array}$ \\
\hline Cleveland, OH (Port) & $11,778,910$ & Iron Ore: $7,233,316$ \\
\hline Detroit, MI (Port) & $14,837,762$ & Iron Ore: $7,299,573$ \\
\hline Duluth-Superior, MN and WI (Port) & $35,102,200$ & Iron Ore: $21,017,361$ \\
\hline Indiana Harbor, IN (Port) & $11,910,541$ & Iron Ore: $8,684,853$ \\
\hline Two Harbors, MN (Port) & $17,208,207$ & Iron Ore: $17,183,537$ \\
\hline
\end{tabular}

The term port is used to distinguish port-level statistics from navigation project (waterway) statistics. One port area may have multiple navigation projects that may handle more tonnage as through-traffic than the amount that docked at the port itself. Tonnage for Calumet Harbor (waterway) is included with other projects that make up the statistical reporting area for Chicago, IL (Port). Additional port and waterway tonnage information is available through the USACE Waterborne Commerce Statistics Center Ports and Waterways Page at http://cwbi-ndc-nav.s3-website-us-east-1.amazonaws.com/files/wcsc/webpub/\#/. (UASCE-WCSC 2020).).

METHOD: This study identified a series of 62 geofenced port areas across the United States based on the location of associated port terminals. To identify each port area, one polygon was drawn to enclose all the associated terminals of that port area; this polygon represented a minimum bounding geometry for port area activity. All port area polygons were created within a shapefile via ArcGIS ArcMap software (ESRI 2019). The boundaries of the six Great Lakes port areas

\footnotetext{
${ }^{1}$ For a full list of the spelled-out forms of the units of measure used in this document, please refer to US Government Publishing Office Style Manual, 31st ed. (Washington, DC: US Government Publishing Office, 2016), 248-52, https://www.govinfo.gov/content/pkg/GPO-STYLEMANUAL-2016/pdf/GPO-STYLEMANUAL-2016.pdf.
} 
discussed in this CHETN are shown in Figure 1; they were selected from the larger suite of 62 port areas. Additional port areas beyond the Great Lakes are mentioned but are not the focus of this CHETN. Historic AIS vessel position information was obtained from the Marine Cadastre website (BOEM and NOAA 2018), which provides a publicly available set of AIS data extracted from the NAIS coverage area across the entire United States, sub-sampled at 1 min intervals. This study used data from years 2015, 2016, 2017, and 2018.

To identify vessel movements between port areas, the following method was employed. First, the AIS position reports that fell within each port area were identified through a geospatial intersection recognition process. Second, the records for a single vessel, as identified by their Maritime Mobile Service Identity (MMSI) number (USCG 2020a),), were extracted and sorted in chronological order to identify the sequence of port area visits across all 62 port areas. Any AIS records without a valid nine-digit MMSI number, or without a valid country code, were excluded from further analysis. This removed $1.05 \%$ of the records across the 4 years of data. To qualify as a port area visit, the longer timespan of the following two conditions was used: more than $1 \mathrm{hr}$ within the polygon or longer than the number of hours for a vessel traveling at $5 \mathrm{kt}$ to transit the longest axis of the port area polygon. Any instance where a vessel left a port area for greater than $24 \mathrm{hr}$ and then returned without appearing in the record at another port area was excluded from further analysis. Third, based on the vessel's self-identified vessel type as broadcast in its AIS message, only vessel types known to engage in commercial cargo movement were retained for further analysis. The vessel types and AIS codes considered in this analysis were Fishing (30), Towing (31, 32), Passenger (60-69), Cargo or integrated Tug Barge (70-79), and Tankers or integrated Tug Tank Barges (80-89) (USCG 2020b). Vessels broadcasting as type code 52 (tugs, light boats, fleet boats, or similar work boats) were deliberately excluded from further analysis because they are not generally carrying cargo or passengers between ports. 


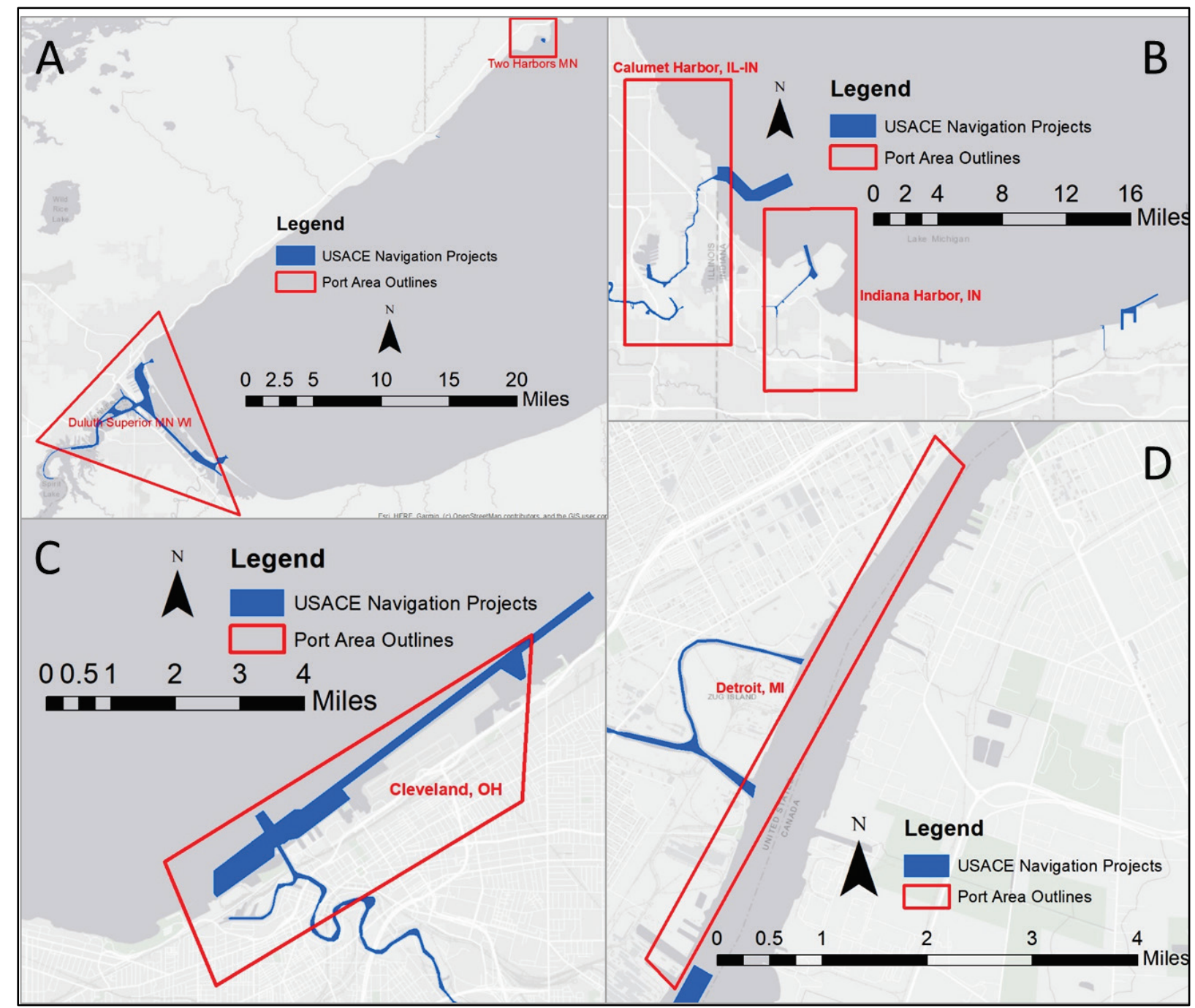

Figure 1. Port area boundaries used in this study. (A) Two Harbors MN and Duluth-Superior MN-WI; (B) Calumet Harbor, IL-IN and Indiana Harbor, IN; (C) Cleveland, OH; (D) Detroit, MI.

The total amount of traffic (arrivals and departures) in each port area for the included vessel types is shown below in Figure 2. The bars in Figure 2 are color coded by vessel type code: fishing vessels in black, tugs in shades of blue, passenger vessels in white or gray, cargo vessels in shades of red and orange, and tanker vessels in shades of green. The total number of all recorded exchanges is indicated by the number at the end of each bar. Vessel exchange types surpassing a threshold of 900 events at a single port area are displayed within curved bubbles, including observed exchanges of 1,916 cargo vessels (AIS type 70) recorded in Cleveland and the comparably sized number of tug vessels (AIS type 31) observed at Indiana Harbor $(2,271)$ and Calumet Harbor $(2,327)$. 


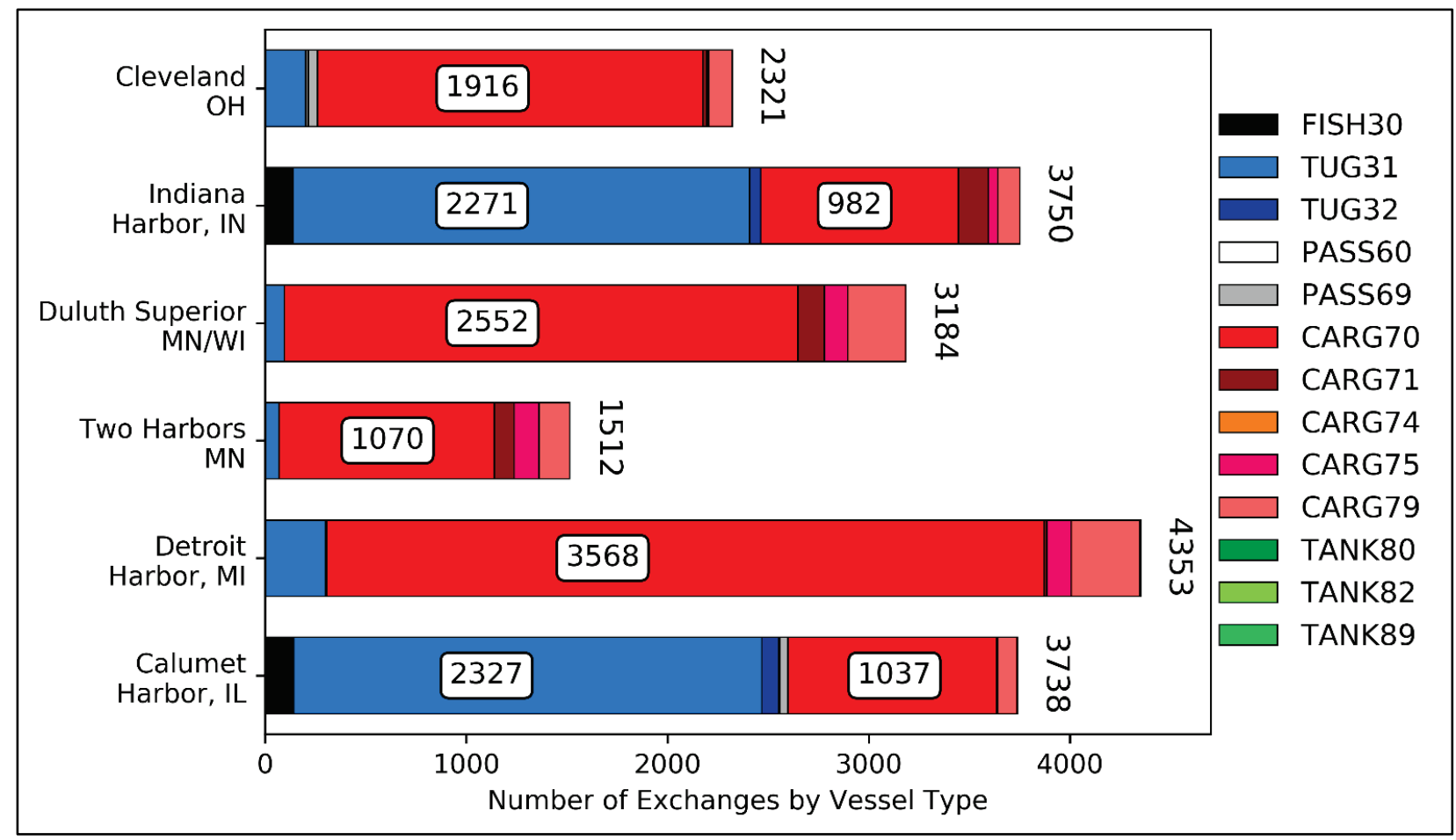

Figure 2. Total vessel exchanges (arrivals and departures) by AIS vessel type code from 2015 through 2018 in select port areas. Abbreviations are as follows: FISH = Fishing; TUG = Tug; PASS = Passenger; CARG = Cargo; TANK = Tanker-type vessels. Numbers in the legend refer to specific AIS vessel type codes (USCG 2020b).

RESULTS: The multi-year record of vessel transits between port areas reveals strong connections between certain port areas within the Great Lakes, as well as connections to other port areas beyond the Great Lakes. For example, Figure 3 shows the monthly count of vessels departing Calumet Harbor, IL-IN, and arriving in other port areas - including those along the Mississippi River as far south as New Orleans, LA. This figure underscores the point that while the Great Lakes may be considered a system-within-a-system that is somewhat self-contained, it is in fact an interconnected part of the larger marine transportation system that extends to ports almost 1,000 mi away. Future work is planned to explore this interconnectivity in greater depth.

For many Great Lakes ports, there is a distinct cyclical pattern of a decline in transits during winter months (generally January, February, and March). Such a pattern is evident in departures from the Detroit port area, which had 60-plus departures in the warmer months but in winter had fewer than 10 per month (Figure 4).). This contrasts with continuous traffic between Calumet Harbor and the neighboring Indiana Harbor. For Calumet Harbor and Indiana Harbor, winter does not stop the regular exchange of vessels between these port areas, although there is an overall decrease in traffic from Calumet Harbor to other port areas included in this study. 


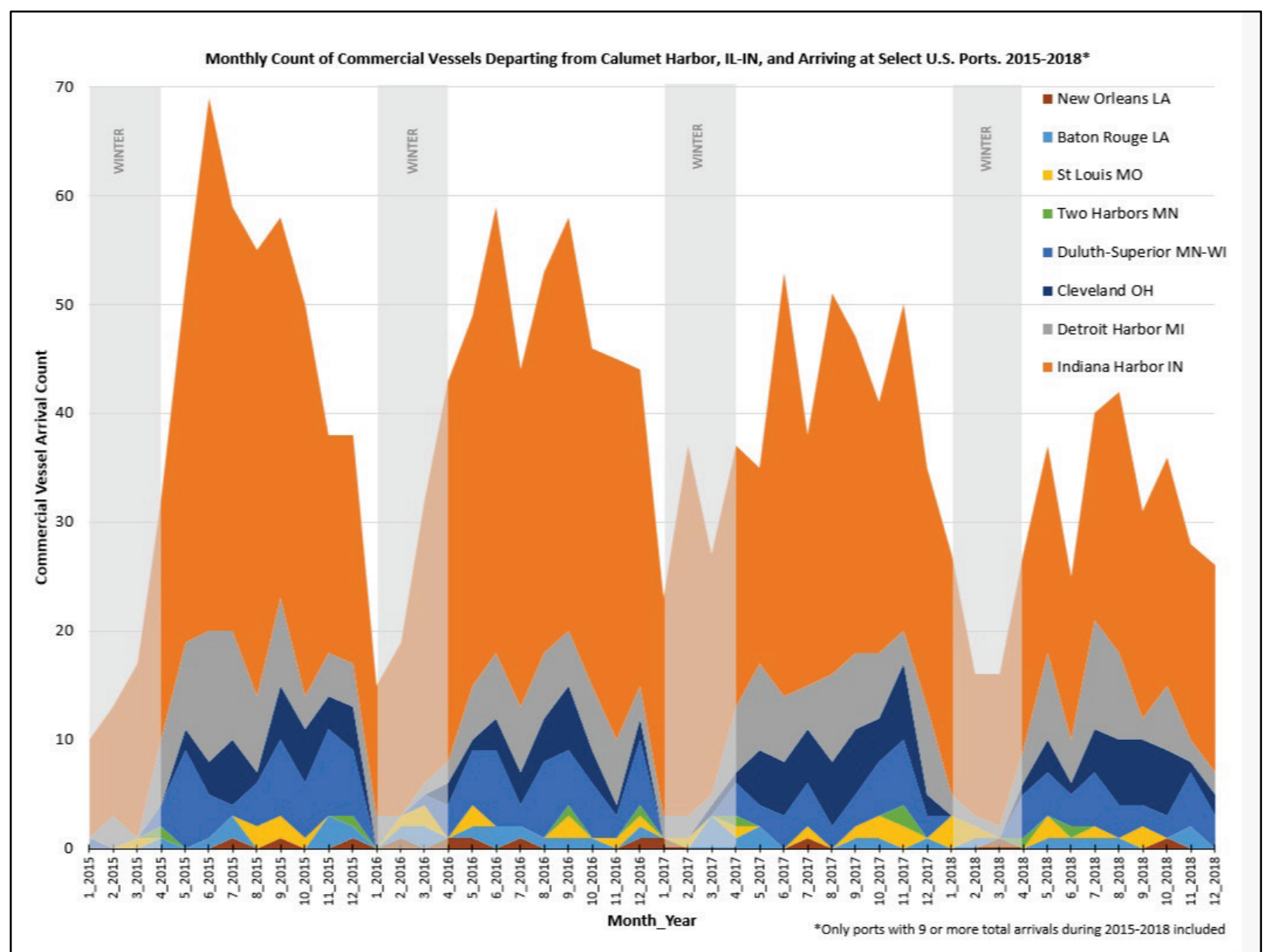

Figure 3. Monthly counts for select commercial vessels departing from the Calumet Harbor, IL and IN, port area and arriving at selected port areas, $2015-2018$. 


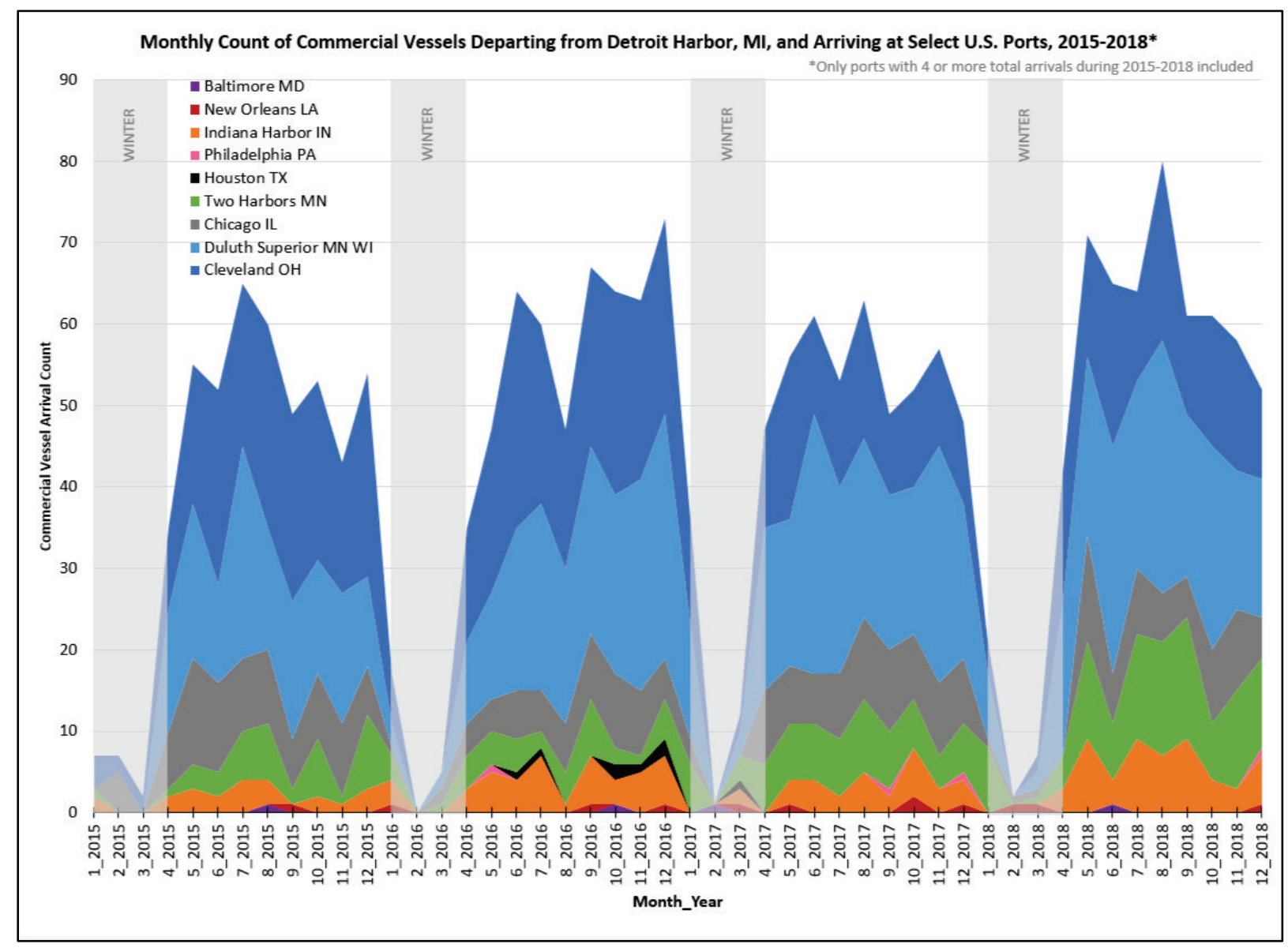

Figure 4. Monthly counts for select commercial vessels departing from the Detroit Harbor, MI, port area and arriving at selected port areas, $2015-2018$.

The level of interconnectivity for the selected port areas and vessel types is presented in Table 2, which provides a monthly summary of departures and arrivals between the port areas. In Table 2 , the rows for winter months of January, February, and March are highlighted in gray, and in many cases the shared traffic between two port areas drops to zero during one or more of the winter months. From these results, the seasonal effects on connectivity between port range port areas is revealed. In terms of shared monthly vessel transits, the port area pair of Calumet Harbor and Indiana Harbor is the strongest pair of any of the six areas considered in this CHETN, with an average 26 monthly transits from Calumet Harbor to Indiana Harbor. This strong connection could be due to vessels exiting from the Mississippi River system stopping in Calumet Harbor and then continuing to the neighboring Indiana Harbor, or vice versa. The next most distinctive port area pair is Cleveland and Detroit, with an average of 17 monthly vessel transits from Cleveland to Detroit. The third most-linked pair in this set was Detroit and Duluth-Superior, with a monthly average of 16 transits from Detroit to Duluth-Superior and 13 transits from Duluth-Superior towards Detroit during the 2015 - 2018 study period. Although AIS data do not include commodity information, the significance of Duluth-Superior in handling iron ore (Table 1) suggests a strong link to heavy manufacturing industries in the Detroit area. 
Table 2. Monthly vessel departures and arrivals by port area (connectivity), selected vessel types, 2015 - 2018. Port areas: Calumet Harbor, IL-IN (CAL); Cleveland, OH (CLE); Detroit, MI (DET); Duluth-Superior, MN-WI (DUL); Indiana Harbor, IN (IND); Two Harbors, MN (TWO). Green color bars indicate increasing numbers within the table range of 0 to 49. Gray rows indicate winter months January, February, and March.

\begin{tabular}{|c|c|c|c|c|c|c|c|c|c|c|c|c|c|c|c|c|c|c|c|c|c|c|c|c|c|c|c|c|c|c|c|}
\hline \multirow{2}{*}{\multicolumn{2}{|c|}{\begin{tabular}{||c|} 
Departure \\
Arrival \\
Year Month
\end{tabular}}} & \multicolumn{5}{|c|}{ Calumet Harbor IL-IN } & \multicolumn{5}{|c|}{ Cleveland $\mathrm{OH}$} & \multicolumn{5}{|c|}{ Detroit MI } & \multicolumn{5}{|c|}{ Duluth Superior MN WI } & \multicolumn{5}{|c|}{ Indiana Harbor IN } & \multicolumn{5}{|c|}{ Two Harbors MN } \\
\hline & & CLE & DET & DUL & IND & TWO & CAL & DET & DUL & IND & TWO & CAL & CLE & DUL & IND & TWO & CAL & CLE & DET & IND & TWO & CAL & CLE & DET & DUL & TWO & CAL & CLE & DET & DUL & IND \\
\hline \multirow{12}{*}{ 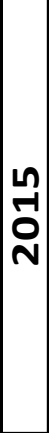 } & 1 & 0 & 0 & 1 & 9 & 0 & 1 & 2 & 0 & 0 & 0 & 0 & 4 & 0 & 2 & 1 & 1 & 0 & 4 & 1 & 2 & 7 & 0 & 1 & 3 & 1 & 0 & 0 & 5 & 0 & 1 \\
\hline & 2 & 0 & 3 & 0 & 10 & 0 & 0 & 0 & 0 & 0 & 0 & 5 & 2 & 0 & 0 & 0 & 1 & 0 & 1 & 0 & 0 & 8 & 0 & 1 & 0 & 0 & 0 & 0 & 0 & 0 & 0 \\
\hline & 3 & 0 & 0 & 0 & 16 & 0 & 0 & 1 & 0 & 0 & 0 & 0 & 2 & 0 & 0 & 0 & 0 & 0 & 0 & 0 & 0 & 16 & 0 & 1 & 0 & 0 & 0 & 0 & 1 & 0 & 0 \\
\hline & 4 & 0 & 6 & 2 & 22 & 1 & 3 & 19 & 0 & 0 & 0 & 7 & 10 & 15 & 2 & 1 & 2 & 1 & 9 & 6 & 4 & 21 & 0 & 1 & 9 & 2 & 1 & 0 & 0 & 3 & 3 \\
\hline & 5 & 2 & 8 & 9 & 33 & 0 & 4 & 26 & 2 & 1 & 0 & 13 & 17 & 19 & 3 & 3 & 6 & 6 & 16 & 7 & 6 & 32 & 2 & 4 & 11 & 2 & 1 & 0 & 4 & 1 & 4 \\
\hline & 6 & 3 & 12 & 4 & 49 & 0 & 3 & 24 & 2 & 1 & 0 & 11 & 24 & 12 & 2 & 3 & 2 & 5 & 11 & 7 & 9 & 49 & 1 & 2 & 11 & 1 & 1 & 0 & 3 & 2 & 7 \\
\hline & 7 & 6 & 10 & 1 & 39 & 0 & 7 & 27 & 7 & 0 & 0 & 9 & 20 & 26 & 4 & 6 & 0 & 8 & 21 & 8 & 11 & 39 & 1 & 2 & 16 & 2 & 0 & 0 & 7 & 3 & 9 \\
\hline & 8 & 1 & 7 & 4 & 41 & 0 & 3 & 27 & 4 & 1 & 0 & 99 & 25 & 15 & 3 & 7 & 2 & 4 & 13 & 10 & 9 & 43 & 0 & 0 & 15 & 3 & 1 & 0 & 6 & 5 & 6 \\
\hline & 9 & 5 & 8 & 7 & 35 & 0 & 6 & 27 & 3 & 3 & 0 & 6 & 23 & 17 & 0 & 2 & 1 & 10 & 11 & 8 & 7 & 35 & 0 & 1 & 12 & 5 & 0 & 0 & 4 & 1 & 10 \\
\hline & 10 & 5 & 3 & 5 & 36 & 0 & 3 & 24 & 1 & 2 & 0 & 8 & 22 & 14 & 2 & 7 & 3 & 7 & 14 & 11 & 9 & 35 & 1 & 3 & 17 & 2 & 1 & 0 & 8 & 3 & 7 \\
\hline & 11 & 3 & 4 & 8 & 20 & 0 & 4 & 19 & 3 & 2 & 0 & 9 & 16 & 16 & 1 & 1 & 0 & 7 & 14 & 3 & 12 & 24 & 1 & 0 & 6 & 0 & 0 & 0 & 7 & 2 & 3 \\
\hline & 12 & 4 & 4 & 6 & 21 & 1 & 3 & 26 & 3 & 1 & 0 & 6 & 25 & 11 & 3 & 9 & 4 & 4 & 9 & 3 & 15 & 21 & 0 & 5 & 7 & 2 & 0 & 0 & 7 & 10 & 4 \\
\hline & 1 & 0 & 3 & 0 & 12 & 0 & 2 & $\| 5$ & 0 & 0 & 0 & 1 & $\| 6$ & 3 & 3 & 3 & 1 & 0 & 3 & 2 & 4 & 10 & 1 & 0 & 2 & 3 & 0 & 0 & 5 & 6 & 3 \\
\hline & 2 & 0 & 0 & 0 & 16 & 0 & 0 & 0 & 0 & 0 & 0 & 0 & 0 & 0 & 0 & 0 & 0 & 0 & 0 & 0 & 0 & 17 & 0 & 0 & 0 & 0 & 0 & 0 & 0 & 0 & 0 \\
\hline & 3 & 0 & 1 & 1 & 26 & 0 & 0 & 2 & 0 & 0 & 0 & 2 & 0 & 2 & 0 & 1 & 0 & 0 & 3 & 0 & 3 & 24 & 0 & 0 & 1 & 0 & 0 & 0 & 2 & 2 & 0 \\
\hline & 4 & 2 & 2 & 3 & 35 & 0 & 4 & 18 & 0 & 0 & 0 & 4 & 14 & 10 & 3 & 4 & 2 & 2 & 8 & 1 & 7 & 37 & 0 & 2 & 7 & 2 & 2 & 0 & 2 & 4 & 6 \\
\hline & 5 & 1 & 5 & 5 & 34 & 0 & 3 & 21 & 1 & 0 & 0 & 4 & 20 & 13 & 5 & 4 & 2 & 4 & 15 & 2 & 6 & 31 & 0 & 1 & 6 & 1 & 0 & 0 & 4 & 4 & 4 \\
\hline$\vec{f}$ & 6 & 3 & 6 & 7 & 41 & 0 & 7 & 34 & 1 & 1 & 0 & 6 & 29 & 20 & 4 & 4 & 5 & 8 & 17 & 3 & 9 & 40 & 0 & 4 & 10 & 1 & 0 & 0 & 5 & 3 & 7 \\
\hline $\mathbf{0}$ & 7 & 3 & 6 & 2 & 31 & 0 & 4 & 25 & 1 & 0 & 0 & 5 & 22 & 23 & 7 & 2 & 3 & 4 & 15 & 0 & 6 & 31 & 1 & 7 & 4 & 2 & 0 & 0 & 5 & 0 & 4 \\
\hline & 8 & 4 & 6 & 7 & 35 & 0 & 4 & 25 & 3 & 1 & 0 & 6 & 17 & 19 & 1 & 4 & 4 & 5 & 16 & 3 & 9 & 34 & 1 & 6 & 2 & 3 & 2 & 0 & 6 & 4 & 5 \\
\hline & 9 & 6 & 5 & 5 & 38 & 1 & 7 & 24 & 0 & 0 & 0 & 8 & 22 & 23 & 6 & 7 & 0 & 4 & 19 & 6 & 12 & 37 & 1 & 5 & 8 & 4 & 1 & 0 & 12 & 4 & 7 \\
\hline & 10 & 3 & 6 & 5 & 31 & 0 & 3 & 29 & 2 & 2 & 0 & 9 & 25 & 22 & 3 & 2 & 3 & 7 & 19 & 5 & 8 & 27 & 2 & 4 & 9 & 2 & 1 & 0 & 5 & 1 & 5 \\
\hline & 11 & 1 & 6 & 2 & 35 & 0 & 3 & 30 & 2 & 0 & 0 & 8 & 22 & 26 & 5 & 1 & 1 & 5 & 23 & 5 & 7 & 35 & 1 & 6 & 7 & 3 & 0 & 0 & 3 & 2 & 7 \\
\hline & 12 & 2 & 3 & 6 & 29 & 1 & 2 & 31 & 0 & 1 & 0 & 5 & 24 & 30 & 6 & 5 & 3 & 5 & 28 & 4 & 9 & 29 & 5 & 3 & 8 & 1 & 0 & 0 & 10 & 1 & 3 \\
\hline & 1 & 0 & 2 & 0 & 20 & 0 & 0 & 10 & 0 & 2 & 0 & 3 & 13 & 14 & 0 & 6 & 1 & 1 & 3 & 3 & 2 & 24 & 0 & 3 & 3 & 1 & 0 & 0 & 7 & 1 & 3 \\
\hline & 2 & 0 & 2 & 0 & 34 & 0 & 0 & 0 & 0 & 0 & 0 & 0 & 0 & 0 & 0 & 0 & 0 & 0 & 0 & 0 & 0 & 30 & 0 & 0 & 0 & 0 & 0 & 0 & 0 & 0 & 0 \\
\hline & 3 & 1 & 1 & 0 & 22 & 0 & 2 & 2 & 0 & 0 & 0 & 0 & 2 & 3 & 2 & 3 & 0 & 1 & 0 & 0 & 3 & 24 & 0 & 0 & 1 & 0 & 0 & 0 & 0 & 2 & 1 \\
\hline & 4 & 1 & 6 & 3 & 24 & 1 & 3 & 17 & 1 & 0 & 0 & 9 & 12 & 20 & 0 & 6 & 2 & 3 & 11 & 6 & 9 & 25 & 3 & 2 & 6 & 1 & 0 & 0 & 10 & 4 & 4 \\
\hline & 5 & 5 & 8 & 2 & 18 & 0 & 4 & 22 & 2 & 0 & 1 & 7 & 20 & 18 & 3 & 7 & 0 & 0 & 13 & 5 & 10 & 18 & 0 & 6 & 7 & 2 & 0 & 0 & 9 & 2 & 6 \\
\hline$\vec{A}$ & 6 & 5 & 6 & 3 & 39 & 0 & 8 & 17 & 4 & 3 & 0 & 6 & 12 & 32 & 4 & 7 & 2 & 8 & 23 & 7 & 10 & 38 & 3 & 3 & 11 & 4 & 0 & 1 & 8 & 4 & 9 \\
\hline & 7 & 5 & 4 & 4 & 23 & 0 & 4 & 18 & 2 & 2 & 0 & 8 & 13 & 23 & 2 & 7 & 5 & 4 & 21 & 6 & 12 & 24 & 5 & 3 & 5 & 3 & 1 & 0 & 12 & 10 & 12 \\
\hline & 8 & 6 & 8 & 2 & 35 & 0 & 5 & 20 & 3 & 3 & 0 & 10 & 17 & 22 & 5 & 9 & 2 & 6 & 16 & 12 & 17 & 34 & 2 & 7 & 11 & 5 & 0 & 0 & 6 & 10 & 7 \\
\hline & 9 & 6 & 7 & 3 & 29 & 0 & 6 & 16 & 2 & 2 & 0 & 10 & 10 & 19 & , & 7 & 1 & 5 & 17 & 7 & 16 & 28 & 2 & 2 & 9 & 2 & 0 & 0 & 10 & 13 & 7 \\
\hline & 10 & 4 & 6 & 5 & 23 & 0 & 1 & 20 & 3 & 1 & 0 & 8 & 12 & 18 & 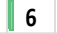 & 0 & 3 & 2 & 16 & 4 & 12 & 22 & 4 & 3 & 9 & 3 & 0 & 0 & 10 & 3 & 7 \\
\hline & 11 & 7 & 3 & 6 & 30 & 2 & 3 & 20 & 3 & 2 & 0 & 9 & 12 & 29 & 3 & 4 & 2 & 6 & 22 & 5 & 20 & 31 & 4 & 4 & 10 & 1 & 0 & 0 & 11 & 8 & 8 \\
\hline & 12 & 2 & 8 & 2 & 22 & 0 & 2 & 14 & 2 & 1 & 0 & 8 & 10 & 19 & 3 & 6 & 0 & 3 & 12 & 3 & 11 & 23 & 4 & 2 & 5 & 2 & 0 & 0 & 11 & 3 & 5 \\
\hline & 1 & 0 & 2 & 0 & 22 & 0 & 1 & $\| 6$ & 0 & 0 & 0 & 1 & 4 & 8 & 0 & 8 & 0 & 0 & 7 & 1 & 4 & 20 & 0 & 1 & 4 & 1 & 0 & 0 & 10 & 3 & 2 \\
\hline & 2 & 0 & 1 & 0 & 13 & 0 & 0 & 0 & 0 & 0 & 0 & 1 & 0 & 0 & 0 & 0 & 0 & 0 & 0 & 0 & 0 & 14 & 0 & 0 & 0 & 0 & 0 & 0 & 0 & 0 & 0 \\
\hline & 3 & 0 & 1 & 0 & 14 & 0 & 0 & $\mid 2$ & 0 & 0 & 0 & 1 & 2 & 2 & 0 & 1 & 0 & 0 & 2 & 0 & 5 & 13 & 0 & 0 & 0 & 0 & 0 & 0 & 1 & 1 & 0 \\
\hline & 4 & 1 & 3 & 4 & 18 & 1 & 5 & 17 & 1 & 0 & 0 & 0 & 16 & 19 & 3 & 4 & 2 & 3 & 7 & 7 & 8 & 18 & 2 & 1 & 7 & 3 & 0 & 0 & 6 & 6 & 5 \\
\hline & 5 & 3 & 8 & 4 & 19 & 0 & 1 & 21 & 3 & 1 & 0 & 13 & 15 & 22 & 9 & 12 & 1 & 5 & 27 & 6 & 17 & 20 & 2 & 5 & 12 & 3 & 0 & 0 & 16 & 9 & \ 7 \\
\hline 6 & 6 & 1 & 4 & 3 & 15 & 1 & 4 & 27 & 1 & 2 & 1 & 6 & 20 & 28 & 3 & 7 & 2 & 5 & 23 & 4 & 15 & 14 & 0 & 5 & 9 & 1 & 0 & 0 & 9 & 7 & 6 \\
\hline & 7 & 4 & 10 & 5 & 19 & 0 & 3 & 18 & 0 & 0 & 0 & 8 & 11 & 23 & 9 & 13 & 1 & 7 & 14 & 4 & 14 & 25 & 1 & 6 & 12 & 1 & 0 & 0 & 16 & 6 & 7 \\
\hline & 8 & 6 & 8 & 3 & 24 & 0 & 5 & 25 & 4 & 0 & 0 & 6 & 22 & 31 & 7 & 14 & 0 & 4 & 28 & 11 & 18 & 24 & 2 & 4 & 14 & 2 & 1 & 0 & 20 & 4 & 6 \\
\hline & 9 & 6 & 2 & 2 & 19 & 0 & 4 & 15 & 6 & 1 & 1 & 5 & 12 & 20 & 9 & 15 & 0 & 3 & 17 & 10 & 11 & 18 & 1 & 8 & $\square 12$ & 1 & 0 & 0 & 16 & 5 & 6 \\
\hline & 10 & 6 & 6 & 2 & 21 & 0 & 6 & 21 & 2 & 0 & 0 & 9 & 16 & 25 & 4 & 7 & 3 & 6 & 17 & 7 & 9 & 19 & 4 & 4 & 11 & 3 & 0 & 1 & 11 & 5 & 5 \\
\hline & 11 & 1 & 2 & 5 & 18 & 0 & 2 & (1) & 2 & 0 & 0 & 10 & 16 & 17 & 3 & 12 & 1 & 4 & 18 & 12 & 9 & 12 & 2 & 9 & 11 & 7 & 0 & 0 & 9 & 5 & 9 \\
\hline & 12 & 2 & 2 & 3 & 19 & 0 & 1 & 19 & 2 & 0 & 0 & 5 & 11 & 17 & 6 & 11 & 1 & 1 & 9 & 8 & 8 & 19 & 4 & 6 & 5 & 3 & 1 & 0 & 13 & 4 & 8 \\
\hline
\end{tabular}


The fourth most-linked pair has an asymmetrical relationship, with an average of eight monthly transits from Duluth-Superior to Two Harbors but an average of three monthly transits from Two Harbors to Duluth-Superior. Because of the proximity of Two Harbors and Duluth-Superior, and their significance for iron ore shipments, this asymmetry suggests the presence of a loop whereby vessels stop at Duluth-Superior, then possibly stop at Two Harbors for additional cargo, and then continue to Detroit (the monthly average from Two Harbors to Detroit was six transits). The identification of multiple-stop loop routes (aka "trip-chaining" events) was outside the scope of this project but is a potential topic for future analysis.

Figure 5 displays a Sankey diagram (Bogart 2021) of the total number of observed transits for selected commercial vessel types from the six Great Lakes study port areas to destination port areas from 2015 through the end of 2018 for port areas pairs with nine or more transits. The strong relationship between Calumet and Indiana Harbor is clearly displayed, as is the strong link between Detroit and Cleveland. However, this diagram raises additional questions for future study. For example, the relatively smaller number of shipments from Great Lakes port areas directly to port areas on the Mississippi River might indicate a precise replenishment schedule at more distant locations, or perhaps relatively smaller - but locally critical - industrial operations that would be affected by disruptions and impacts to ports not typically anticipated in a regional context. With this perspective, it becomes apparent that a disruption of cargo flows at origin port areas on the Great Lakes may cause supply chain disruptions in geographically distant locations down the Mississippi River and that these types of cascading disruptions might not be evident or anticipated within a regionally limited study area. Therefore, is it important to distinguish between a metric describing the breadth of destinations supplied by a single port (geographical reach) from a metric describing the relative level of connectedness between ports (connectivity). Both such metrics have been presented in this paper and warrant greater examination in conjunction with commodity flow information, which is not available within AIS messages.

Quantifying port area connectivity, including the geographic extent of connectivity, temporal patterns, recent trends, and commodity movements between interconnected port pairs, is a fundamental contribution to any attempt to study or improve maritime resilience. For example, any shipment moving from the western end of the Lake Superior to ports in Illinois, Indiana, Ohio, the lower peninsula of Michigan, or the Wisconsin coast of Lake Michigan, must pass through the navigation locks at Sault Ste. Marie (the Soo Locks). This analysis observed 1,656 such transits of vessels departing from the Duluth-Superior or Two Harbors port areas and moving to the other four Great Lakes port areas (Calumet Harbor, Cleveland, Detroit, or Indiana Harbor) during the 2015 - 2018 study period (this number does not include vessels transiting westward into Lake Superior). This supports the idea that assets beyond port area boundaries, such as navigation locks or ice breaker vessels, serve as an essential component of regional resilience. 


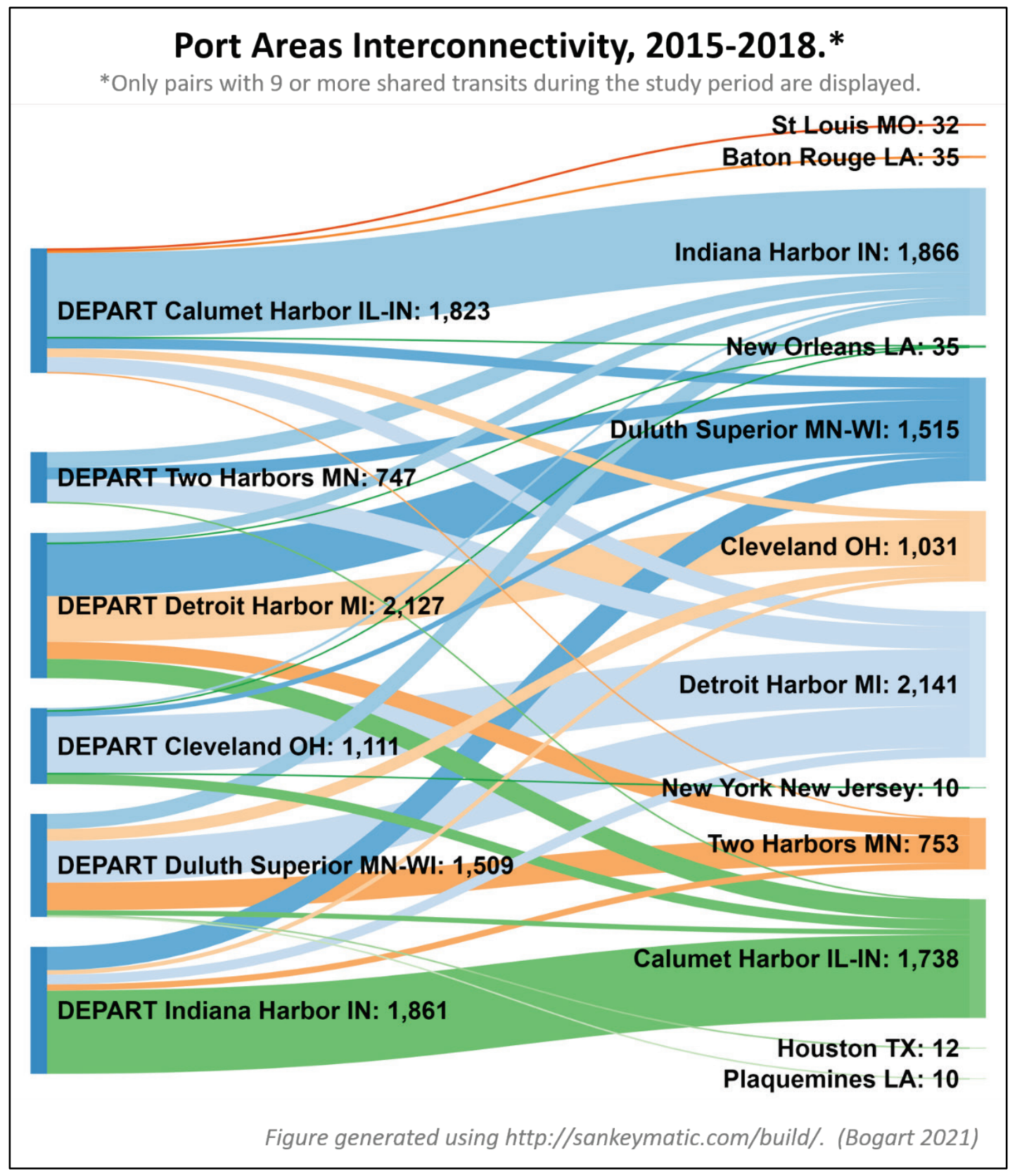

Figure 5. Commercial vessel departures from Great Lakes port areas and arrivals at other selected port areas, $2015-2018$.

Future work on the topic of port area connectivity and its relation to North American supply chain resiliency is ongoing and contributes to a greater need to develop resilience metrics to describe USACE project performance. The present analysis may be expanded to include additional US and Canadian port areas within the Great Lakes and along the St. Lawrence Seaway. Additional aspects of future work may include a focus on specific supply chains known to rely on bulk commodities, additional years of data as available through the Marine Cadastre website, or more in-depth examinations of the geographical connectedness of a single port area. 
ADDITIONAL INFORMATION: This CHETN was prepared by Marin Kress, Marin.M.Kress@usace.army.mil, US Army Engineer Research and Development Center, Coastal and Hydraulics Laboratory. The Open Researcher and Contributor ID (ORCiD) numbers for the authors are the following: Marin M. Kress 0000-0002-5835-5686; David L. Young 0000-00034886-1304; Katherine F. Chambers 0000-0003-3558-386X; and Brandan M. Scully 0000-00018641-2142. Special gratitude is extended to the USCG NAIS program and the Marine Cadastre collaboration (https://marinecadastre.gov/). In addition, appreciation is expressed to Tanya Beck and Mitchell Brown for thoughtful review of an early draft of this CHETN.

This CHETN is funded by the USACE Navigation Systems Research Program and should be cited as follows:

Kress, M. M., D. L. Young, K. F. Chambers, and B. M. Scully. 2021. AIS Data Case Study: Quantifying Connectivity for Six Great Lakes Port Areas from 2015 through 2018. ERDC/CHL CHETN-IX-56 Vicksburg, MS: US Army Engineer Research and Development Center. http://dx.doi.org/10.21079/11681/40720

\section{REFERENCES}

Asadabadi, A., and E. Miller-Hooks. 2020. "Maritime Port Network Resiliency and Reliability through Co-opetition." Transportation Research Part E: Logistics and Transportation Review 137: 101916. https://doi.org/10.1016/j.tre.2020.101916

Aven, T. 2017. "How Some Types of Risk Assessments Can Support Resilience Analysis and Management." Reliability Engineering \& System Safety 167: 536-543.

Bogart, S. 2021. SankeyMATIC. "Build a Sankey Diagram.” Accessed January 25, 2021. http://sankeymatic.com/build/

BOEM (Bureau of Ocean Energy Management) and NOAA (National Oceanic and Atmospheric Administration). 2018. Automatic Identification System (AIS) Data. Accessed January 23, 2019. https://marinecadastre.gov/ais

ESRI. 2019. ArcMap 10.7.1. [software program]. Redlands, CA. https://support.esri.com/en/products/desktop/arcgisdesktop/arcmap/10-7-1

IALA (International Association of Marine Aids to Navigation and Lighthouse Authorities). 2008. Establishment of AIS as an Aid to Navigation: Report ID 1062. https://www.iala-aism.org/product/establishment-of-ais-as-an-aidto-navigation-1062/

IEC (International Electrotechnical Commission). 2001. EC 61993-2: 2001-12 Maritime Navigation and Radiocommunication Equipment and Systems — Automatic Identification Systems (AIS) - Part 2: Class A Shipborne Equipment of the Universal Automatic Identification System (AIS) - Operational and Performance Requirements, Methods of Test and Required Test Results. Technical standards report. https://www.iec.ch/index.htm

ITU-R (International Telecommunications Union - Radiocommunication Sector). 2014. Recommendation ITU-R M.1371: Technical Characteristics for an Automatic Identification System Using Time Division Multiple Access in the VHF Maritime Mobile Frequency Band. Report. https://www.itu.int/rec/R-REC-M.1371/en

Kress, M. M., B. J. Tetreault, K. N. Mitchell, M. Balazik, and M. C. Booton. 2020. AIS Data: Real-Time Operation Support, Incident Investigations, and Waterway Use Analysis. ERDC/CHL CHETN-IX-53. Vicksburg, MS: US Army Engineer Research and Development Center. http://dx.doi.org/10.21079/11681/36395 
Lam, J. S. L., and W. Y. Yap. 2011. "Dynamics of Liner Shipping Network and Port Connectivity in Supply Chain Systems: Analysis on East Asia." Journal of Transport Geography 19(6): 1272-1281.

Mitchell, K. N., and B. N. Scully. 2014. "Waterway Performance Monitoring via Automatic Identification System (AIS) Data." Transportation Research Record: Journal of Transportation 2426(1): 20-26. https://doi.org/10.3141/2426-03

Mohamed-Chérif, F., and C. Ducruet. 2016. "Regional Integration and Maritime Connectivity across the Maghreb Seaport System.” Journal of Transport Geography 51: 280-293

Omer, M., A. Mostashari, R. Nilchiani, and M. Mansouri. 2012. "A Framework for Assessing Resiliency of Maritime Transportation Systems." Maritime Policy \& Management 39(7): 685-703. https://doi.org/10.1080/03088839.2012.689878

Pavlov, A., D. Ivanov, D.. Pavlov, and A. Slinko. 2019. “Optimization of Network Redundancy and Contingency Planning in Sustainable and Resilient Supply Chain Resource Management under Conditions of Structural Dynamics." Annals of Operations Research 1-30. https://link.springer.com/article/10.1007/s10479-019-03182-6

PIANC (The World Association for Waterborne Transport Infrastructure). 2019. Guidelines and Recommendations for River Information Services. InCom Working Group Report Number 125/I-2019. https://www.pianc.org/publications/inland-navigation-commission/wg125-1

Scully, B. M., and K. F. Chambers. 2019. "Measuring Port Disruptions with Automatic Identification System Data." Ports 2019: Port Planning and Development. Reston, VA: American Society of Civil Engineers.

Touzinsky, K. F., B. M. Scully, K. N. Mitchell, and M. M. Kress. 2018. "Using Empirical Data to Quantify Port Resilience: Hurricane Matthew and the Southeastern Seaboard." Journal of Waterway, Port, Coastal, and Ocean Engineering 144(4): 05018003. https://ascelibrary.org/doi/10.1061/\%28ASCE\%29WW.1943-5460.0000446

USACE (US Army Corps of Engineers). 2017. US Army Corps of Engineers Resilience Initiative Roadmap. US Army Corps of Engineers Engineer Pamphlet EP 1100-1-2: 16 October 2017. Washington, DC: USACE, Headquarters. https://www.publications.usace.army.mil/Portals/76/Publications/EngineerPamphlets/EP 1100-1-2.pdf?ver=tFqTiymAdTxMOi8 BPAXA\%3d\%3d

USACE (US Army Corps of Engineers). 2020. Implementation of Resilience Principles in the Engineering and Construction Community of Practice. CECW-EC. 29 May 2020. Washington, DC: US Army Corps of Engineers, Headquarters, https://www.wbdg.org/FFC/ARMYCOE/COEECB/ecb_2020_6.pdf

USACE-WCSC (US Army Corps of Engineers, Waterborne Commerce Statistics Center). 2020. Waterborne Commerce Statistics Center - Data for Downloading. https://publibrary.planusace.us/\#/series/Data\%20for\%20Downloading

USCG (US Coast Guard). 2018. Navigation Center: Automatic Identification System Overview. http://www.navcen.uscg.gov/?pageName=AISmain

.2020a. Navigation Center: Maritime Mobile Service Identity. https://www.navcen.uscg.gov/?pageName=mtmmsi

.2020b. Navigation Center: USCG AIS Encoding Guide, v.25. https://www.navcen.uscg.gov/pdf/AIS/AISGuide.pdf

US Code of Regulations. 2019. Title 33-Navigation and Navigable Waters. "Part 164-Navigation Safety Regulations." 33 C.F.R. § 164.46. Washington, DC. https://www.govinfo.gov/content/pkg/CFR-2019-title33-vol2/xml/CFR2019-title33-vol2-part164.xml

Young, D., and B. Scully. 2018. "Assessing Structure Sheltering via Statistical Analysis of AIS Data." J. Waterway, Port, Coastal, and Ocean Engineering 144(3): 04018002. https://doi.org/10.1061/(ASCE)WW.1943-5460.0000445

NOTE: The contents of this technical note are not to be used for advertising, publication or promotional purposes. Citation of trade names does not constitute an official endorsement. 